\title{
¿’Donde manda capitán no gobierna marinero"? \\ El trabajo marítimo en el Río de la Plata (Argentina), 1890-1920
}

\section{Laura Gabriela Caruso( ${ }^{(\star)}$}

\section{Resumen}

Este artículo se propone reconstruir las formas del trabajo a bordo, la organización y proceso de trabajo marítimo, en tanto una de las dimensiones de la historia de los trabajadores marítimos del Río de la Plata, sus características (composición de las secciones, tareas, calificaciones) y condiciones de trabajo en los años que van desde 1890 a 1920. Al haber constituido un grupo de significativa visibilidad, tanto por lo central de la actividad que realizan en la estructura económica nacional como por sus acciones sindicales, se aborda aquí el estudio de una de las dimensiones de la experiencia de los trabajadores embarcados, la laboral, desarrollada a bordo de las embarcaciones que operaban al interior del puerto o que navegaban río arriba hasta Matto Grosso, Asunción del Paraguay, las ciudades del Litoral o la costa patagónica.

Palabras clave:Trabajo maritimo (Argentina), proceso de trabajo, condiciones laborales

\section{Abstract}

This work aims to rebuild forms of work on board, organization and maritime, workflow as one of the dimensions of the history of maritime workers in the Río de la Plata, their characteristics (composition of sections, tasks and qualifications) and working conditions in the years ranging from 1890 to 1920. To the have formed a group significant visibility, both central activity in national economic structure and its Union actions addressed here study of one of the dimensions of the experience of the on-board workers, the labour, developed aboard vessels operating within the port or they that sailed upstream until Matto Grosso, Asunción in Paraguay, the cities of the coast or the Patagonian coast.

Keywords: Maritime work (Argentina), labor process, onboard labor conditions 


\section{Introducción}

$\mathbf{E}$ transporte marítimo fue una actividad central en la estructura económica de la Argentina y en el proceso de su incorporación a la economía mundial capitalista. El mismo se encontraba a cargo de los trabajadores marítimos. El desarrollo y consolidación de una infraestructura de transporte que permitiera la exportación y comercialización de la producción nacional incluyó, junto al tendido de la red ferroviaria, la constitución de una flota mercante fluvial. Los obreros que navegaban por ríos y costas constituyeron uno de los engranajes fundamentales en la actividad económica, y tuvieron un lugar de importancia en el proceso de formación de la clase obrera argentina. Lo estratégico de su labor fortaleció su posición con relación a las empresas del sector y a los sucesivos gobiernos a la hora de reclamar por sus reivindicaciones. Esta posición estructural privilegiada y el desarrollo de una organización sindical unificada entre las diferentes secciones posibilitaron la realización exitosa de acciones de lucha y fue la base para el control del trabajo, su ingreso y condiciones en la segunda década del siglo XX.

Durante los primeros años del siglo existieron diversos intentos por constituir una organización sindical unificada por parte de los obreros embarcados. Así lo evidencia la acción conjunta de las Sociedades de Marineros y de Foguistas, y la aparición en 1907 de la Liga Obrera Naval. Tras estas experiencias, en 1910 se creó la Federación Obrera Marítima (FOM), uno de los primeros sindicatos por rama, de carácter nacional, al frente del cual se encontraban militantes obreros de la corriente sindicalista. La FOM llegó a ser una de las organizaciones más importantes del movimiento obrero argentino en las primeras décadas del siglo XX y uno de los pilares de la Federación Obrera Regional Argentina, Noveno Congreso (FORA IX), la principal central sindical en esos años, dirigida por la misma corriente. ${ }^{1}$

Sin embargo, este significativo lugar en la realidad histórica del trabajo en la Argentina no encontró su correlato en las producciones historiográficas.

\footnotetext{
1 El sindicalismo fue una corriente dominante entre los trabajadores y sus organizaciones en las década de 1910, dirección de la FOM y de la FORA XI. Centrándose en el control obrero sobre las condiciones de la propia actividad, las luchas dirigidas por los sindicalistas de la FOM desafiaron el poder patronal sobre el proceso de trabajo, la selección de la mano de obra y las condiciones laborales. Marcada por un fuerte obrerismo, antiintelectualismo y apoliticismo, reivindicaron la acción directa y la autoeducación obrera por medio de la lucha sindical. Afirmaban al sindicato como la organización privilegiada para la dirección obrera, en detrimento del partido político. En Argentina, los sindicalistas se constituyeron en una corriente autónoma en el año 1906, al ser expulsados del Partido Socialista, al cual cuestionaban por su parlamentarismo y su escaso arraigo en los sindicatos. Al frente de importantes organizaciones sindicales, su orientación política fue virando hacia posturas más corporativas-economicistas, centradas en la defensa incondicional de la herramienta gremial, el sindicato, y abandonando progresivamente la confrontación abierta, para reemplazarla por una táctica pragmática y centrada en la negociación. Ver Daniel Kersffeld, George Sorel: apóstol de la violencia, Buenos Aires, Signo, 2005; Alejandro Belkin, Sobre los orígenes del sindicalismo revolucionario en Argentina, Departamento Historia, Buenos Aires, CCC, 2007; Maricel Bertolo, Una propuesta gremial alternativa: el Sindicalismo Revolucionario (1904-1916), Buenos Aires, CEAL, 1993; Hugo Del Campo, El sindicalismo revolucionario (1905-1940), Buenos Aires, CEAL, 1986.
} 
En contraste con la extensa bibliografía existente en torno a los trabajadores ferroviarios, un sector evidentemente clave del transporte, los estudios históricos de las últimas décadas en la Argentina han prestado escasa o nula atención a los problemas y procesos relacionados con los obreros marítimos. Su experiencia laboral, sindical y política es una historia aún por escribirse. En esta perspectiva, el presente artículo avanza en el conocimiento de las formas del trabajo marítimo, a partir de la reconstrucción de su materialidad primera, del proceso de trabajo y la organización laboral, así como las condiciones que regían el trabajo, a bordo de las embarcaciones fluviales del Río de la Plata.

El estudio de los modos y formas del trabajo a bordo, su organización y sus transformaciones habilita al conocimiento del desarrollo cotidiano del trabajo de los obreros en las embarcaciones de cabotaje, y permite así reconstruir una de las múltiples dimensiones de la historia de un grupo obrero que tuvo dentro del conjunto de los trabajadores un papel importante en el desarrollo sindical y político de la clase obrera argentina en las primeras décadas del siglo $\mathrm{XX}$. Los documentos que permiten desarrollar el análisis son variados y pocas veces visitados en la historiografía local. Los periódicos gremiales, como La Unión del Marino, El Boletín del Obrero Mecánico y El Maquinista Marítimo, junto con publicaciones estatales como el Boletín del Departamento Nacional del Trabajo, así como leyes y reglamentos de la Prefectura General de Puertos y censos nacionales correspondientes al período en cuestión, son los documentos que sustentan el presente análisis.

Los trabajadores marítimos fueron aquellos marineros de diversos rangos y funciones, foguistas, maquinistas, oficiales, mozos, cocineros, ayudantes de maquina o de cubierta, que, embarcados en buques mercantes pertenecientes en su mayoría a empresas de bandera nacional, realizaban travesías por los ríos y costas de la Argentina y países limítrofes. Estos realizaban sus tareas diarias a bordo de grandes vapores, veleros, remolcadores y lanchas, entre las muchas embarcaciones que navegaban la cuenca del Plata u operaban al interior del Puerto de Buenos Aires. Eran obreros que manejaban, mantenían, limpiaban y habitaban los barcos mercantes, realizando a bordo diversas tareas que requerían diferentes calificaciones. El control de la entrada y salida de los barcos de los puertos argentinos, en especial en aquellos puertos artificiales que requerían el uso de remolcadores para el atraque de los transatlánticos u otros barcos de gran calado, como era el caso de Buenos Aires, suma un elemento explicativo de la contundencia de las acciones de estos trabajadores. Tal como afirmara el historiado Edgardo Bilsky: "Dominar las vías de comunicación, el puerto, es dominar el flujo de la vida económica. Y esto será rápidamente comprendido por el movimiento obrero". ${ }^{2}$

Edgardo Bilsky, La FORA y el movimiento obrero /1, Buenos Aires, CEAL, 1985, p. 53. 
El escenario más amplio de esta historia fue el Río de la Plata y su principal puerto, Buenos Aires, desde el que se establecieron conexiones regionales, nacionales e internacionales. El mismo constituyó un espacio de expresión temprana e intensa del conflicto obrero-patronal y fue también el lugar donde trabajadores y empresarios, a través de sus organizaciones corporativas y políticas, desplegaron sus estrategias.

Las embarcaciones fueron el escenario particular del trabajo a bordo. Estos barcos provenían de lugares tan diversos como el Matto Grosso, Asunción del Paraguay, el Alto Paraná, los pueblos y ciudades del Litoral, Montevideo y otros puertos uruguayos, la costa patagónica o la brasileña, o tenían a estos como destino. Existían además gran cantidad de otras embarcaciones menores que operaban dentro de las instalaciones del puerto, en el trasbordo de mercaderías, pasajeros o tripulantes.

Cabe destacar algunas de las características particulares del trabajo marítimo, ya que influyeron en gran medida en la conformación de la experiencia laboral. Así, su fuerte estacionalidad, marcada por los ritmos de la producción agropecuaria, hacía que en la época de cosecha, durante los meses de verano, la actividad de carga y descarga de los productos a ser vendidos en los mercados internacionales sea más intensa. Esto elevaba la demanda de mano de obra en el puerto y a bordo, generando una coyuntura de auge del empleo, a la vez propicia para plantear acciones de lucha diversas. ${ }^{3}$ De hecho, la mayoría de las huelgas declaradas por las organizaciones sindicales marítimas se produjeron entre diciembre y febrero, incluso en el periodo aquí considerado, se inició con una huelga a fines 1890 , declarada por la Sociedad de Marineros, y se cierra con una huelga iniciada en febrero de 1920, que terminará siendo una de las huelgas más prolongadas en la historia del país.

En segundo lugar, un rasgo que por característico puede parecer obvio, fue la contratación predominante, cuasi exclusiva, de varones adultos para realizar las faenas a bordo. Esto hizo del trabajo marítimo un ámbito masculino, por el tipo de tareas a realizar, la fuerza y resistencia requeridas, y por la particularidad de ser un trabajo que se realizaba en un tiempo y un espacio alejados del hogar, embarcando a veces por varios días o semanas según el caso.

Tercero, el trabajo marítimo estuvo también signado por la gran movilidad internacional de su mano de obra durante todo el período, atravesado por la Gran Guerra y las crisis económicas. Inmigrantes italianos y croatas, entre muchos otros, fueron parte fundamental de las tripulaciones de las flotas fluviales. Cabe destacar que a partir de la Ley de Cabotaje, sancionada en el año 1910 y que exigía un porcentaje de estos sean nativos o naturalizados argentinos, se dio

Ofelia Pianetto, "Mercado de trabajo y acción sindical en la Argentina, 1890-1922" en Desarrollo Económico vol. 24, No. 94, Santiago, Cepal, 1984, pp. 297-307. 
una tendencia a la argentinización, más pronunciada entre los oficiales, pero igualmente existente entre la tripulación. ${ }^{4}$ En el caso de los trabajadores de la Sala de Máquinas, recién en 1915, con la incorporación de un nuevo reglamento, se estipuló la nacionalidad de los maquinistas, los que debían ser ciudadanos argentinos en el caso del jefe de sala o primer maquinista.

Por último y con relación a la condición de inmigrantes de la mayoría de los obreros embarcados, esto mismo sumado a la propia naturaleza de la actividad, hizo del trabajo marítimo una experiencia regional, la cual no admitió fronteras nacionales. Los trabajadores que realizaban la navegación comercial sobre las aguas de Uruguay, Paraguay, Brasil y Argentina transitaban sus fronteras geográficas y políticas. El viaje volvía difusas tales divisiones, haciendo de los marítimos los trabajadores internacionales por antonomasia. La doble condición de inmigrantes y trabajadores a bordo posibilitaban una percepción más inmediata de la pertenencia a un grupo humano sin fronteras, el cual compartía condiciones de existencia y de explotación. Como afirma Vitor Wagner Neto de Oliveira, el ser internacionales favorecía en estos trabajadores ciertas posiciones internacionalistas, dotándolos de una condición de posibilidad, necesaria no suficiente, para el desarrollo de una identidad clasista caracterizada por un internacionalismo, en tensión con otras identidades, como la profesional, la étnico-cultural o la nacional, sobre las que prevaleció en los primeros años del siglo XX. ${ }^{5}$

\section{A bordo de las embarcaciones fluviales}

El trabajo de tripulantes y oficiales se desarrolló en barcos a vapor, veleros, lanchas, barcazas, pontones, remolcadores y otros tipos de embarcaciones. Su estructura, su maquinaria y demás características diagramaron tareas y funciones, siendo el sustrato material de las formas del trabajo a bordo. En su tensión en el lugar de trabajo, obreros y patrones delinearon concepciones y valores a partir de los intereses que se contraponían en la labor cotidiana, organizándose y actuando en torno a estos. Así, en el escenario particular del trabajo marítimo se condensaron relaciones económicas, sociales y políticas significativas que hacen necesario su estudio. En tanto primera aproximación al universo laboral, la reconstrucción del proceso y organización del trabajo y sus cambios, permite conocer la experiencia obrera en el campo de la producción misma, destacando el carácter conflictivo del trabajo, de la tecnología, sus relaciones y transformaciones. ${ }^{6}$ De esta forma,

\footnotetext{
4 Aurelio y Anselmo Climent González, Historia de la Marina Mercante Argentina, tomo IV, Buenos Aires, 1972. La Ley de Cabotaje No. 7.049, del año 1910, estipuló en primer lugar que la navegación fluvial o de cabotaje, entre puertos interiores, quedaba reservada a embarcaciones de bandera nacional, las que obligatoriamente debían tener un capitán o patrón argentino así como la cuarta parte de su tripulación. Al pertenecer al pabellón nacional una embarcación podía, a partir de esta ley, no pagar ciertos derechos de entrada, faro, balizas, sanidad y visa consular en puertos nacionales y de algunos países limítrofes. Dicha ley fue reemplazada en 1918 por la Ley No. 10.606.

5 Víctor Wagner Neto De Oliveira, Entre o Prata e Mato Gresso: uma viagem pelo mundo do trabalho marítimo de 1910 a 1930 (Buenos Aires, Montevidéu, Assunção e Corumbá), Campinas, UNICAMP, 2006.

6 Mirta Lobato, La vida en las fábricas. Trabajo, protesta y política en una comunidad obrera, Berisso (19041970), Buenos Aires, Prometeo, 2001.
} 
el proceso de trabajo, en tanto herramienta conceptual y metodológica, se constituye en una dimensión explicativa importante para comprender las formas de explotación, la experiencia laboral, sus tensiones y características, así como también las formas sindicales y políticas desarrolladas por los trabajadores.

A la hora de conocer las condiciones en las que se realiza el trabajo de miles de obreros embarcados desde un punto de vista cualitativo, analizando el proceso de trabajo y sus formas particulares, uno de los aspectos fundamentales a considerar es su base técnica, la estructura material sobre la cual se desplegó la explotación del trabajo y sus modificaciones. La máquina a vapor, la multiplicación del número de calderas, el uso de turbinas y de motores diesel, así como los cascos de hierro o acero y la hélice, fueron algunos de los cambios más importantes que se implementaron en la industria marítima mundial y también en la Argentina. Las embarcaciones a motor y con casco metálico se utilizaron en forma generalizada en nuestro país en las últimas décadas del siglo XIX. Si se observa el tonelaje de registro, es decir, la capacidad de carga en vapores ó veleros, se hace evidente el predominio de los primeros. Ya en 1880 el 65,3 \% del tonelaje comercializado se transportó en barcos a vapor; en 1914 el porcentaje ascendía al 90 \%. ${ }^{7}$ La utilización de la máquina a vapor presentó también algunos problemas, como por ejemplo, el alto consumo de carbón, el que además de tener un costo elevado, ocupaba gran cantidad de espacio para almacenarlo.

Estas transformaciones produjeron a la vez una reducción de los tiempos de viaje y una mejor calidad, en función de una mayor regularidad y seguridad. También posibilitaron triplicar la capacidad promedio de bodega o carga, que pasó de 348 a 1.121 toneladas entre 1880 y 1914 . Al mismo tiempo, la tripulación media necesaria a bordo descendió entre 1895 y 1914 de 20 a 8 tripulantes por barco. De esta forma, los cambios se tradujeron en un sustancial aumento de la productividad del trabajo, tanto en la velocidad como en la capacidad del transporte, a la vez que hicieron posible una reducción de la cantidad de fuerza de trabajo empleada a bordo. ${ }^{8}$

El paso de la navegación a vela a la navegación a vapor fue uno de los cambios fundamentales en la industria marítima mundial. Con él se avanzó en la mecanización del trabajo, ya que el motor dio una nueva base objetiva al proceso de trabajo en la navegación, imponiendo formas y ritmos, determinando en buena medida su organización y la existencia de diversas categorías y tareas. Aparecieron así los maquinistas, foguistas, auxiliares, entre otros, quienes operaban, realizaban tareas de mantenimiento, alimentaban, reparaban y limpiaban la máquina.

\footnotetext{
Tercer Censo Nacional levantado el 1ro. de junio de 1914, tomo 10, Buenos Aires, Talleres Gráficos de L. J. Rosso, 1916-1917.

Datos de elaboración propia a partir de los censos nacionales: Segundo Censo de la República, Buenos Aires, Talleres Tipográficos de la Penitenciaría Nacional, 1898, y Tercer Censo Nacional levantado el $1^{\circ}$ de junio de 1914.
} 
Junto con la implementación de la máquina a vapor se produjeron otros cambios, entre los cuales el más importante fue el paso de la madera al metal en la construcción del casco y la estructura de las embarcaciones. La utilización de la madera, por sus características, limitaba la capacidad de las embarcaciones y las hacía más inestables y precarias, por su dificultad de conseguir estanqueidad. ${ }^{9}$ Tras algunas construcciones mixtas, el hierro se impuso por sus ventajas, y sólo será reemplazado por el acero ya entrado el siglo XX. En 1895 el 88\% de los vapores censados tenían casco de hierro; en 1914, el 92\%. El nuevo material permitió la construcción de buques de mayores dimensiones, aumentando la capacidad de carga e incrementando el volumen de mercancías que podían transportarse en un viaje. El hierro y la mayor potencia generada por las máquinas a vapor u otros motores hicieron posible el aumento de la velocidad. Más carga en menos tiempo, ambos factores hicieron más productivo el trabajo a bordo.

Existieron otras innovaciones que buscaban mejorar el funcionamiento de la máquina a vapor y la utilización del espacio a bordo. Una de estas, que ayudo a aumentar la presión y potencia del motor, fue el cambio en la forma de las calderas, que de cuadradas pasaron a ser cilíndricas o tubulares. Otras modificaciones apuntaban a disminuir el consumo de carbón y aumentar la potencia, llegando a implementarse un sistema mixto de máquina de vapor y turbinas. Finalmente, la propia máquina a vapor fue reemplazada. En los primeros años de la década de 1910 comenzó a ser sustituida por el motor de combustión interna o Diesel, el que, al no necesitar alimentación externa de ningún tipo, permitió suprimir calderas y carboneras, liberando espacio y capacidad para el transporte de una cantidad mayor de mercancías. A la vez, por su mayor potencia y velocidad, el motor diesel acortó en gran medida los tiempos de viaje. Un indicio de la mayor presencia de este tipo de motores en la flota mercante argentina lo constituyó la sanción del Reglamento de Conductores y Maquinistas de Motores Marinos de Combustión Interna, realizada en 1912 por decreto del Poder Ejecutivo Nacional. ${ }^{10} \mathrm{La}$ creciente implementación del motor diesel significo un número cada vez mayor de obreros abocados a manejar, reparar, mantener y limpiar la maquina, proceso que se vio expresado, por ejemplo, en la constitución de la Federación de Trabajadores de Combustión Interna en abril de 1917, en la región del Alto Paraná. ${ }^{11}$

Con relación a la motivación de armadores y empresarios para introducir estos cambios en el proceso de trabajo, es claro que las modificaciones e innovaciones en la estructura de los barcos respondieron al problema fundamental de las empresas de navegación de cabotaje, y de las empresas marítimas en general, que fue reducir los costos del viaje, acortar sus tiempos y acrecentar a la vez los

9 Calidad de estanco, esto es, no hacer agua en casco y cubierta, lo cual se consigue calafateando las juntas de las maderas con estopa o algodón impregnado en sebo o alquitrán.

${ }_{10}$ A. y A. González Climent, Historia de la Marina; Recopilación de antecedentes que interesan a la Marina Mercante y Policía Marítimas, Buenos Aires, 1937, Ordenanza 2333, 27 noviembre 1912

11 La Unión del Marino (LUM) No. 64, junio 1920, Boletín del Departamento Nacional del Trabajo (DNT); No. 65, julio 1920. 
beneficios obtenidos, a la vez sobreviviendo o imponiéndose en la competencia. Buscaron para esto formas, materiales, máquinas y equipos que hicieran más eficiente el tiempo de viaje y aumentaran su seguridad, reduciendo posibles pérdidas. La lógica subyacente no es otra que la de aumentar la productividad del trabajo, permitiendo con este aumento una creciente reproducción ampliada de sus inversiones. Estos cambios fueron, además de una necesidad de la competencia, un arma política de los patrones, posibilitando el desplazamiento de trabajadores y el ataque a su poder y organización sindical. La Compañía de Navegación Argentina Nicolás Mihanovich fue una de las empresas marítimas que adoptó estas innovaciones en forma temprana. Esta se convirtió en la empresa naviera más importante del tráfico de cabotaje a principios del siglo XX mediante un proceso de concentración y centralización de capitales, a partir de la incorporación de la mayoría de sus competidoras por compras sucesivas, llegando a cuasi monopolizar los viajes por el Litoral, la costa uruguaya y la brasileña. En su flota figuraron las embarcaciones más veloces y modernas, la mayoría de ellas construidas en Inglaterra.

Por otro lado, el avance de la mecanización y objetivación del proceso de trabajo implicó independizar de la pericia humana al trabajo a bordo, y con ello, simplificó tareas, a la vez que creó nuevos oficios o categorías de trabajadores, y eliminó otras. Los cambios en el proceso de trabajo tuvieron consecuencias para el trabajador marítimo, entre las que es posible identificar en primera instancia, la reducción del número de trabajadores necesarios. Esto puede mensurarse a partir de la cantidad de trabajadores que constituían la tripulación media por embarcación, la que se redujo de 20 a 8 entre 1895 y 1914. Del conjunto de la tripulación, la más afectada por las transformaciones del proceso de trabajo fue la sección de sala de máquinas. Comparando la información que brindan los censos para los años 1895 y 1914, la cantidad de foguistas disminuyó en un 42\%, a la vez que el número de maquinistas lo hizo en un $40 \%$.

Junto al descenso del número de trabajadores a bordo, la incorporación de cambios en la base material del trabajo se tradujo en la desaparición de ciertas ocupaciones. Por ejemplo, el remplazo de la madera por el hierro como material del casco implicó la disminución en numero e importancia del oficio del calafate. ${ }^{12} \mathrm{~A}$ su vez, en los barcos a motor ya no fueron necesarios todos los conocimientos, pericias y maniobras relacionados con el velamen que constituían hasta entonces parte central de las tareas de los marineros en cubierta. Del mismo modo, la incorporación de nuevas maquinas devinieron en la aparición de nuevos trabajadores, como los engrasadores, electricistas y otros obreros dedicados a mantener y limpiar las nuevas maquinas, así como también produjeron la disminución y progresiva eliminación de foguistas y carboneros, al prescindir de la alimentación externa del motor. Una evidencia de este proceso la constituye el pliego de condiciones de las tripulaciones en huelga del Alto

$\overline{12}$ Este trabajador se encargaba de sellar las juntas de la madera del casco con brea y estopa. 
Paraná, de principios de 1918, en el que no aparecen foguistas ni carboneros, y si el personal de motores de combustión interna y engrasadores. ${ }^{13}$ Así, el conjunto de cambios y transformaciones en el proceso de trabajo marítimo y en su organización derivó en múltiples conflictos y medidas de lucha por parte de los trabajadores y sus organizaciones sindicales desde incluso los últimos años del siglo XIX.

\section{En viaje: tareas, categorías y calificaciones}

Hay tres clases de individuos: los que viven, los que mueren, y los que están en la mar

(Refrán popular)

Las embarcaciones que recorrieron ríos y costas y aquellas que circulaban dentro del puerto fueron el lugar de trabajo de marineros, foguistas y mozos, entre muchos otros obreros que constituían las tripulaciones. Junto a los barcos a motor existieron una gran cantidad de embarcaciones menores a vela, con diferentes funciones y estructuras según su número y tipo de velamen. Goletas, balandras y pailebotes fueron los más característicos en los ríos argentinos. (Ver la siguiente tabla)

Tabla 1: Personal embarcado en las flotas de bandera nacional

\begin{tabular}{|c|c|c|c|}
\hline Veleros & Tripulación & Oficialidad & Total \\
\hline 1895 & 4.865 & 1.967 & 6.832 \\
\hline 1914 & 3.925 & 5.329 & 9.254 \\
\hline \multicolumn{4}{|c|}{ Vapores } \\
\hline 1895 & 3.854 & 211 & 4.065 \\
\hline 1914 & 8.301 & 1.545 & 9.846 \\
\hline
\end{tabular}

Elaboración propia en base a datos del Segundo Censo Nacional (1895)

y Tercer Censo Nacional (1914)

La importancia de la navegación a motor desde 1880 y su acelerado avance constituye en un dato de la realidad histórica de la navegación fluvial, sustentado en las cifras arriba mencionadas. Sin embargo, su probada importancia en el país desde fines del siglo XIX, no quitó que a bordo de los veleros siguieran desarrollando su trabajo una gran cantidad de obreros marítimos.

En 1914 la cantidad de personal total embarcado abocado a los veleros y la de los barcos a motor era similar. Sin embrago, al considerar la diferencia entre tripulación y oficialidad, surgen realidades contrastantes. La cantidad de obreros

13 LUM No. 64, junio 1920, Boletín del DNT No. 65, julio 1920. 
embarcados o tripulación fue mayor en los vapores, mientras que en los veleros, cada vez menos utilizados para los viajes de mayor carga, predominaban los patrones de pequeñas embarcaciones, los que se clasificaban como parte de la oficialidad.

El trabajo desarrollado por estos obreros marítimos en los barcos que arribaban y zarpaban del Puerto de Buenos Aires, o que operaban por sus canales y diques, estaba organizado en diversas secciones, con una estructura y categorías bien definidas. Del conjunto de la tripulación, algunas nos resultan más familiares, como pueden ser los marineros o maquinistas. Sin embargo, existían múltiples tareas que se desarrollaban a bordo, organizadas en las secciones de máquinas, la de cubierta y la de cámara o cocina. Esta organización del trabajo sigue siendo aún hoy la estructura básica del trabajo marítimo. En cada una de estas tres secciones existía una jerarquía claramente establecida, que diferenciaba a la oficialidad de la tripulación, y también las diversas tareas y calificaciones al interior de cada una de estas secciones. Estos trabajadores de ríos, puertos y costas pertenecían así a una de las tres secciones en las que se organizaban las tripulaciones fluviales.

\section{En cubierta: marineros y oficiales}

Encargada de realizar los servicios de navegación, las maniobras del buque, el manejo del velamen, las operaciones de carga y descarga de bodegas, la sección cubierta estaba compuesta por el capitán, los oficiales auxiliares, junto a prácticos o baqueanos, y por una tripulación constituida por diversas categorías de marineros. El marinero de mayor experiencia, el contramaestre, coordinaba a la tripulación de cubierta y controlaba la eficaz realización de las tareas de los marineros, que consistían en la carga y descarga de mercadería, el manejo de grúas, tareas de amarre, control de las bodegas, limpieza y mantenimiento de cubierta, apertura y cierre de escotillas, tendido de toldos y guardias en el puente de navegación. También se encargaban del mantenimiento de equipos, aparejos y velámenes $\mathrm{u}$ otros artefactos en los vapores, así como de picar la pintura y renovarla, y de lustrar los equipos e instalaciones de metal. Entre los marineros encontramos a bodegueros, timoneles y faroleros, según las tareas a las que fueran asignados. Completaban la tripulación de cubierta aquellos que manejaban los guinches o grúas, y los grumetes o aprendices de marineros. El contramaestre recibía órdenes del oficial jefe de cubierta y las transmitía a los marineros, ejecutando y supervisando el plan de carga y descarga. ${ }^{14}$

El capitán era la figura más compleja a bordo, por su posición en relación con empresa y/o armador y con la tripulación, así como por sus funciones y poderes, otorgados por el derecho de navegación. La carrera para llegar a ser

14 Yadira De Las Cuevas Potrony, "Regulación Jurídica de la gente de mar. Aspectos significativos en el ordenamiento jurídico cubano", en Revista Académica No. 33, La Habana, Equipo Federal de Trabajo, 1989. 
la autoridad máxima a bordo transitaba diversas categorías, pilotín, piloto, capitán de cabotaje o fluvial, hasta capitán de ultramar. ${ }^{15}$ Para adquirir el título o habilitación expedido por la Prefectura General de Puertos, el aspirante debía dar cuenta de una amplia y compleja gama de conocimientos, como astronomía, geografía del continente americano, trigonometría, meteorología, derecho comercial marítimo, lengua, gramática y otros más. Los requisitos y exigencias de ingreso dan cuenta del trabajo altamente calificado que constituía la profesión de capitán. En el año 1917 el examen se rendía en la Escuela Nacional de Pilotos, de reciente creación. Los aspirantes debían ser mayores de edad, acreditar 3 años de experiencia en navegación y contar con un certificado de aptitud física y otro de buena conducta. ${ }^{16}$

La responsabilidad máxima que tenía el capitán se aplicaba, por ley, a todo lo acontecido a bordo, desde las maniobras del buque en viaje y en puerto, la gestión de actividades comerciales y la documentación necesaria, la contratación y manejo de la tripulación, de los pasajeros, de las tareas de carga y descarga, las comunicaciones, y podríamos seguir enumerando. Además estaba habilitado a constituirse en representante legal del propietario o armador, e incluso en situaciones de excepción podía ejercer funciones públicas, tales como las policiales (policía de seguridad, de navegación, judicial, sanitaria, aduanera y migratoria), notariales (confección de testamentos e inventarios) y de registro civil. ${ }^{17}$ En la reglamentación existente la figura del capitán y su autoridad aparecía fuertemente reafirmada, tanto como delegado de la autoridad marítima, del Estado y como representante de la empresa. Existió también un especial énfasis en la necesidad de respetar su autoridad y las disposiciones por él determinadas, afirmando la disciplina a bordo y respetando la escala de jerarquías sobre cuya base estaba organizado el trabajo. ${ }^{18}$

La posición compleja del capitán en particular, y de la oficialidad en general, con relación al conjunto de los trabajadores embarcados no impidió que las organizaciones gremiales del personal jerárquico se hayan aliado en ciertas coyunturas con los sindicatos de la tripulación, como ocurrió entre 1916 y 1921, cuando estos desarrollaron una acción conjunta de confrontación con las empresas. El hecho de poseer un mayor conocimiento del proceso de trabajo y de su organización, junto al contacto fluido y directo con los armadores, dejaba en manos de la oficialidad la toma de decisiones vitales con respecto al trabajo a bordo. Este fue uno de los motivos por el cual la unidad de acción entre la FOM y el Centro de Capitanes y otros gremios de oficiales fue decisiva para el desarrollo exitoso de las luchas obreras en esos años.

15 Recopilación de antecedentes que interesan a la Marina Mercante y Policía Marítimas, Buenos Aires, 1937, pp. 386-389.

${ }_{16}$ Recopilación de antecedentes, pp. 402-420. Programa de exámenes para capitanes, pilotos, pilotines y patrones de 1906, y ampliación de mayo de 1911.

17 Roberto Bloch, "La figura del Capitán”, en Revista Marítima, Buenos Aires, abril 1999.

18 Recopilación de antecedentes, pp. 388-389. 
La cantidad de oficiales necesarios era estipulada para cada embarcación según su tonelaje y función. Los oficiales de primera, segunda o tercera categoría tenían a cargo diversas tareas. El primer oficial, o jefe de cubierta, estaba a cargo de la ejecución de todo lo decidido por el capitán, en temas como el diagrama y ejecución del plan de carga y estiba, mantenimiento de los instrumentos y equipos de cubierta, conducción del personal, tareas administrativas como la asignación de turnos y de horas extras. El segundo oficial era responsable de la actualización de las cartas de navegación. El tercer oficial, además de asistir a los otros, debía garantizar el cuidado y mantenimiento del equipo de salvamento e incendio, los botes y balsas salvavidas, extintores portátiles, sistema de alarmas y detectores contra incendio y sistemas fijos de extinción de incendios. ${ }^{19}$

Los capitanes de barcos pequeños eran llamados patrones. Estos, responsables de una lancha, chata u otra embarcación menor, podían ser sus propietarios o estar empleados por una empresa de navegación. Constituían un grupo particular dentro de la estructura sindical marítima, ya que, si bien eran considerados pilotos de menor rango, la mayoría se organizaron sindicalmente junto a la tripulación. Capitanes y patrones eran responsables de la conformación de la tripulación y de la entrega del listado correspondiente a la Prefectura y a la Aduana. ${ }^{20}$

\section{En el corazón del barco: la sala de máquinas}

...Hoy no se mueve una cosa a bordo sin que el maquinista tenga que intervenir; hoy podemos decir que la navegación es mecánica... el maquinista hoy a bordo es el factorum, podemos decirlo, y si no, pruebas: que los pescantes no funcionan bien, allá va el maquinista; que la luz eléctrica anda mal, el maquinista tiene que ir a ver que hay; que el molinete no va bien, allá va el maquinistas... pero nadie se acuerda de que allá abajo, en el estómago del buque, casi en la quilla encerrados, van unos cuantos hombres velando por la seguridad de todos... ${ }^{21}$

La dirección y conducción de la máquina motor y los mecanismos auxiliares del buque, incluyendo los sistemas eléctricos, se ejercía desde la sala de máquinas. Allí trabajaban foguistas, carboneros, caldereros, pañoleros, limpiadores, electricistas, engrasadores, mecánicos y ayudantes, quienes, en turnos de entre 4 y 6 horas, se dedicaban a alimentar las calderas, vigilar, limpiar y mantener en estado la maquinaria.

El jefe o primer maquinista era responsable del funcionamiento y mantenimiento de la maquina principal y de las auxiliares, de la asignación de los turnos y horas extras, y del cálculo de consumo de combustible y agua para alimentar al

19 Recopilación de antecedentes, p. 388.

20 Recopilación de antecedentes, tomo 3, p. 212.

21 El Maquinista Marítimo, Buenos Aires, $1^{\circ}$ mayo 1902, p. 1, "Los maquinistas navales mercantes". 
motor. Debía además coordinar las reparaciones de envergadura con los talleres correspondientes y con el armador. Otras tareas, como vigilar el funcionamiento de calderas y máquinas auxiliares, el mantenimiento del equipo eléctrico y las reparaciones menores estaban a cargo de segundo oficial, con la colaboración de un tercer oficial maquinista, de ser necesario. Los maquinistas necesitaban de la previa y expresa autorización del capitán para cualquier modificación, tanto para reparar averías como para alterar el régimen normal de la marcha del motor.

Para ser maquinista marítimo debía rendirse un examen en la Prefectura, que incluía conocimientos de aritmética, geometría, álgebra, física, dibujo e información sobre calderas y accesorios, dependiendo de la categoría a la que se buscaba acceder. ${ }^{22}$ Desde 1898 el oficio estaba reglamentado, ${ }^{23}$ definiendo así la cantidad de maquinistas y foguistas para cada embarcación de acuerdo a la potencia de la máquina y a los turnos y guardias a cubrir. ${ }^{24}$ Sin embargo, existieron reiteradas demandas del sindicato de maquinistas por el incumplimiento de dicho reglamento, denunciando la cantidad insuficiente de maquinistas diplomados. ${ }^{25}$

Según el reglamento, modificado en 1907 y 1915, todos los postulantes a maquinista debían rendir un examen. Las categorías eran: conductor de máquinas, ayudante, primer, segundo, tercer maquinista, o maquinista superior. Por ejemplo, para acceder a la habilitación como maquinista de tercera categoría, se debía contar con 180 días de navegación como ayudante a bordo, con certificado de buena conducta, ser mayor de 20 años y de haber tenido una entrevista con la comisión examinadora, presidida por el Prefecto General. Había además que rendir un examen, con una parte oral y otra escrita, y que incluía ejercicios de aritmética, geometría e información de máquinas de vapor y calderas. El diploma de maquinista de primera exigía además unos 360 días de navegación como maquinista de segunda, y demostrar conocimientos prácticos en desmonte, ajuste y montaje de una máquina, realizar su limpieza interna y saber sobre los materiales de su construcción, aleaciones y características. ${ }^{26}$

Por lo general en cada embarcación había un maquinista, cuyo nivel de formación dependía del tipo, función, tonelaje y potencia de la máquina del barco. Por ejemplo, las embarcaciones menores requerían sólo un conductor de máquina, quien obtenía su certificado tras dos años de experiencia foguista y saber leer y escribir. En el otro extremo se encontraban los maquinistas superiores, requeridos en buques de pasajeros de ultramar con máquinas de más de 2.500 c.f.; entre estas dos situaciones existía una escala de posibilidades.

Junto al maquinista existían otros trabajadores: allí estaban los pañoleros, encargados de las herramientas y materiales, y los caldereteros, que alimentaban

Boletín del Obrero Mecánico, Año II, No. 8, Buenos Aires, agosto 1900

Recopilación de antecedentes, tomo 5, p. 1-16.

Boletín del Obrero Mecánico, Año II, No. 1, Buenos Aires, enero 1900, pp. 2.5.

Boletín del Obrero Mecánico, Año II, No. 8, Buenos Aires, agosto 1900.

Recopilación de antecedentes. 
de agua las calderas. La mayoría de los trabajadores de esta sección estaba compuesta por los foguistas, cuya tarea principal era alimentar el fuego de la máquina motor. Al cargar, activar, retirar, tapar y apagar los fuegos de las calderas, hacían posible su funcionamiento. También estaban los limpiadores, la categoría más baja entre la tripulación de máquinas.

Con la aparición de otros tipos de motores se hicieron necesarios nuevos oficios y especialistas, como los electricistas y engrasadores. Los primeros eran trabajadores calificados con certificado habilitante, a cargo del mantenimiento de los equipos eléctricos a bordo, mientras que los engrasadores ayudaban al maquinista en las tareas de control y mantenimiento de la maquinaria.

\section{Otras secciones y oficios a bordo}

La sección de cocina o cámara estaba abocada a la atención de los camarotes y la cocina del barco, así sea de los pasajeros o de la propia tripulación. La misma estaba conformada por un mayordomo a cargo, cocineros, mozos, auxiliares, camareros y personal de servicio, quienes eran los únicos eximidos de la condición de saber nadar para ser contratados a bordo. ${ }^{27}$

El pedido de víveres y el control del stock, así como la elaboración del menú, estaba a cargo del primer mozo. Además había mozos y auxiliares que realizaban las tareas de limpieza de la cocina y los instrumentos utilizados, de los comedores, pasillos, y camarotes, a la vez que colaboraban con la preparación del servicio. En algunas tripulaciones se sumaban despenseros a cargo de la administración y del inventario de los víveres a bordo.

$\mathrm{Al}$ adoptarse el telégrafo se creó la sección de comunicaciones, compuesta por uno o más operadores, encargados de mantener y monitorear la estación de radio. La ley de Instalaciones Radiotelegráficas fue sancionada por el Congreso de la Nación en abril de 1913, mediante la cual se estipuló que las comunicaciones de este tipo quedarían a cargo del Estado. Disponía como obligación para todo buque de más de 50 personas (entre tripulantes y pasajeros) llevar un equipo o telégrafo y una persona capacitada para su utilización.

Las embarcaciones que ingresaban a los puertos o ríos argentinos tenían además la obligación de llevar un baqueano o un práctico, según fuera el tipo de embarcación y su tonelaje. ${ }^{28}$ El baqueano era un conocedor de las cualidades de una determinada zona fluvial, de sus canales y arroyos, cañadas, picadas y bañados. Especializado en los temas relacionados con las rutas fluviales y la geografía de una región particular, el baqueano asesoraba al capitán o al patrón de una embarcación en su travesía que en ciertos tramos se hacía dificultosa de

27 Oscar Troncoso, Fundadores del gremialismo obrero, vol. 1, Buenos Aires, CEAL, 1983, p. 56.

28 Recopilación de antecedentes, Reglamento del Puerto de Buenos Aires, febrero 15 de 1894. 
navegar, o en el ingreso a determinados puertos. Para poder realizar este trabajo debía obtenerse el título correspondiente, para lo cual existían dos opciones. La primera consistía en acreditar por lo menos cinco años de experiencia práctica, siendo argentino, menor a 65 años y poseer conocimientos de lectoescritura. Con relación a este último requisito, si no sabia leer y escribir tenía un año para aprender y volver a rendir dicho examen. La otra posibilidad era rendir un examen ante una comisión compuesta por prácticos de los puertos de la zona, el que consistía en demostrar en la práctica el manejo de luces de navegación, remolque y fondeo, timón y telégrafo, maniobra de anclas, medición de calados y conocimientos de embarcaciones menores, reglamentación de pitadas, maniobras diurnas y nocturnas, canales y acciones antes coalición o abordaje. ${ }^{29}$

Los prácticos eran aquellos expertos que dirigían el rumbo de las embarcaciones para que al ingresar a puerto lo hagan en forma segura. Este era, y es aún hoy, un trabajo de gran calificación, que requería del conocimiento pormenorizado de las características del río o puerto en cuestión. Todos los avances tecnológicos existentes, faros, balizas, satélites, radares, pilotos automáticos por mencionar algunos, no han podido suplantar a este oficio altamente calificado, y por lo tanto, escaso. Para acceder a este puesto era necesario tener una formación previa como capitán y rendir un extenso examen en Prefectura. Como responsables de ingresar o sacar los buques de los puertos a los que eran asignados, su profesión y habilitación estaban reguladas por el Estado. El examen por el cual obtenían esta habilitación estaba a cargo de la Prefectura, y para rendirlo, además de acreditar un conocimiento pormenorizado de las características del puerto al que iban a ser asignados o a la vía navegable a la que iban a abocarse en su tarea, era necesario poder sondear el calado (medir la profundidad) del río o canal, para bien maniobrar los buques al entrar y salir del puerto o al adentrarse por los ríos interiores.

El practicaje era un servicio que se abonaba de acuerdo con las características de la embarcación. Las tarifas, así como otras disposiciones generales del oficio, fueron estipuladas por Reglamento General de Prácticos, sancionado por decreto presidencial en 1905. Un nuevo reglamento, sancionado en 1917, estableció la jurisdicción única como área de competencia del práctico, especializado en una zona o puerto en particular. Además, fijaba la cantidad necesaria de prácticos por jurisdicción. Por ejemplo, en el Puerto de Buenos Aires se empleaban 40 prácticos, en el Río de la Plata 70, un número similar al del Río Paraná, mientras que al Río Uruguay le correspondían 10 prácticos. Los prácticos se organizaron desde principio de siglo en la Sociedad Cuerpo de Prácticos de Argentina, cuyos estatutos y personería jurídica fueron aprobados por decreto presidencial en $1904 .^{30}$

29 Recopilación de antecedentes, Decreto del Ministerio de Marina, mayo 2 de 1911, ordenanza de Prefectura del 10 de mayo de 1911.

30 A. y A. González Climent, Historia de la Marina. 
Las tareas y funciones que caracterizaban al trabajo a bordo se hacían más complejas y diversas si se trataba de un buque de pasajeros, multiplicándose el personal de servicio y el administrativo, así como aquel personal a cargo de áreas recreativas y médicas. La organización del trabajo a bordo se caracterizó además por la variada conformación de la tripulación, en número y tareas, según el tipo de embarcación, tonelaje, función y destino, así como por la potencia de la máquina que la impulsaba. Por ejemplo, por ordenanza de Prefectura, en 1915 un buque de 100 toneladas de registro debía tener una tripulación de 18 hombres, incluido el capitán. Sin embargo, para cumplir con una jornada laboral de ocho horas, la misma embarcación necesitaba un total de 27 tripulantes. Contra toda regla, un barco de 200 toneladas podía perfectamente zarpar con 16 tripulantes a bordo, incluyendo al capitán, al primer y segundo oficial, tres maquinistas, un contramaestre, seis marineros, un foguista, un cocinero y un mozo, como de hecho ocurría sin sanción legal. ${ }^{31}$

Otra característica del trabajo marítimo fue la marcada diferenciación entre la tripulación y la oficialidad, apreciable tanto en las tareas diarias, en los saberes requeridos, así como también en su organización gremial. Las diferencias jerárquicas y la estructuración piramidal del trabajo a bordo se destacan así como rasgos característicos de la organización laboral, expresados en los registros censales y plasmados en extensas escalas salariales. Quizás sea esta una de las características más importantes del trabajo marítimo, con relación a otros tipos de trabajos, como por ejemplo el que podían desempeñar trabajadores de una fábrica, de la administración pública o de una empresa privada. Cotidianamente, en la vida y las tareas a bordo, estaba presente esta diferencia: oficiales y tripulantes habitaban y trabajaban en espacios diferenciados, comían y dormían en lugares distintos. Muy a pesar de estar dentro del mismo buque, un maquinista podía no ver al jefe de máquinas durante varios turnos, lo mismo un marinero o cualquier otro tripulante con respecto al capitán.

La diferenciación jerárquica y de categorías entre los trabajadores embarcados, como se mencionó, estuvo expresada en la forma de nucleamiento sindical que estos desarrollaron. La organización más importante de la tripulación fue la FOM, la cual agrupó desde su formación, en 1910, a marineros y foguistas, e incorporó con el tiempo a mozos y patrones, contramaestres, conductores y ayudantes. Cada una de estas categorías mantuvo su sindicato, considerado una sección dentro de la estructura federativa de la FOM, compuesta además por otras secciones geográficas, como Campana, San Nicolás, Rosario, Gualeguaychú, Bahía Blanca, entre muchas otras.

La FOM participó en muchas de las luchas obreras generales más significativas del periodo, e impulsó una serie de huelgas generales y parciales en el sector,

31 Luis Ario Russo, La marina mercante argentina, Buenos Aires, Instituto de Economía de los Transportes/FCE/UBA, 1938, pp. 216-221. 
bajo la dirección de la corriente sindicalista. ${ }^{32}$ Lo hizo muchas veces, y de forma exitosa entre 1916 y 1921, en forma conjunta con los gremios de la oficialidad, entre los cuales estuvieron el Centro de Capitanes de Ultramar, la Sociedad de Prácticos y Baqueanos, el Centro de Maquinistas Navales, Centro de Comisarios Navales y el Centro de Radiografistas. ${ }^{33}$ Esta unidad contradecía la disciplina laboral a bordo, basada en la aplicación y respeto de las jerarquías y responsabilidades, e invocada por las empresas y sus organizaciones y sancionada por la reglamentación existente. Dicha alianza posibilitó la unidad de acción que resultó vital para el control sindical de la organización del trabajo. El control obrero efectivo sobre el trabajo tuvo como eje la acción conjunta y solidaria de los capitanes. Estos, junto a los maquinistas, fueron actores centrales, dado que era el personal más calificado y los responsables, no sólo de la navegación, sino también de la selección de personal idóneo para las diversas secciones y categorías.

La misma organización jerárquica del trabajo a bordo, si bien generó conflictos reiterados, también produjo determinados consensos. Estos consentimientos básicos, consolidados y compartidos por las tripulaciones, por los oficiales, y por las organizaciones sindicales de ambos, fueron también abonados por las empresas y por el Estado. Una de las nociones básicas fue la existencia misma de la jerarquización de tareas y funciones, así como la necesaria disciplina y respeto a esa estructura. El fundamento de este consenso estaba dado por la conciencia de que, en viaje, una falla, un descuido o la falta de acuerdo podían tener consecuencias peligrosas: la supervivencia misma daba sentido a la organización piramidal. Esto hizo que la existencia misma de una jerarquía y la figura del capitán y demás partes de esta estructura piramidal no fueran cuestionadas por las organizaciones sindicales en las que participaban los trabajadores marítimos, dejando espacio así a otro tipo de planteos, como los de unidad y solidaridad. El llamado a la tripulación a sostener una actitud tolerante y disciplinada, y a mantener el "respeto al superior, sin que por ello os veáis obligados a rebajar vuestra propia dignidad" fue realizado desde las paginas del periódico sindical, junto a la apelación a oficiales y tripulantes subalternos a "sed tolerantes, en el amplio sentido de la palabra, en el cumplimiento de vuestros respectivos cargos". ${ }^{34} \mathrm{Al}$ mismo tiempo se alentaba a los oficiales a sostener la unidad de acción sindical en contra de la patronal, contra los, "muchos oficiales de la marina mercante que poseen aún, ya sea por falta de cultura y conciencia gremial o por cualquier otro prejuicio de clase o favoritismo patronal, cierto espíritu de desconfianza hacia sus respectivos sindicatos". ${ }^{35}$

El refrán popular, y que aún lo es hoy, que afirmaba "donde manda capitán no gobierna marinero", hace referencia a las fuertes determinaciones de la

\footnotetext{
Ver nota 1.

33 Boletín de La Unión del Marino No. 21, Buenos Aires, junio 9 de 1920.

34 LUM No. 59, enero 1920, Welko Denda, "Reflexiones del momento. La disciplina".

35 LUM No. 55, septiembre 1919, W. Denda, "Un llamado a los oficiales".
} 
jerarquía y la disciplina en la vida y trabajo a bordo, intrínsecas al trabajo a bordo y compartidas por los que en él participaban. De todas formas, la acción gremial conjunta y la unidad entre la oficialidad y la tripulación logró poner en un primer plano otro tipo de tensiones, ya no aquellas propias de la labor en las diferentes embarcaciones, sino el enfrentamiento común contra la patronal. En resumen, la jerarquía fue un elemento central en la organización del trabajo a bordo, considerado como tal por las organizaciones sindicales de los diversos trabajadores y del personal jerárquico marítimo. Sin embargo, tal diferenciación entre secciones y al interior de cada una de estas no impidió la unidad de acción, la cual se desarrolló durante el periodo de mayor conflictividad, entre los años 1916 y 1921. Durante las huelgas marítimas dirigidas por la FOM, en diciembre 1916, abril 1917, enero 1919 y durante todo el año 1920, participaron marineros, foguistas y mozos, aliados con los capitanes y maquinistas. Además de sostener una unidad de acción, lograron en varias oportunidades constituir un Comité de Huelga, como ocurrió en 1919 y 1920. La alianza desarrollada en esos años por los sindicatos de la tripulación, la oficialidad y otros trabajadores calificados, enfrentó las condiciones de trabajo dolosas impuestas a bordo por las empresas, las que fueron en parte revertidas a través de la organización y la lucha conjunta.

\section{Los problemas de la gente de mar: labores, descanso y reglamentación}

Marinos que viven entre máquinas... Foguistas, hombres de mar... que por virtud de tales, tienen proposición de aprender más que aquel trabajador que nunca salió de su aldea ${ }^{36}$

El trabajo marítimo, organizado en la forma antes descripta, tuvo como base objetiva al barco, cuyo proceso de trabajo definió tareas, ritmos y funciones, intensidades, jornadas y condiciones, objetos de diversas reglamentaciones y leyes. Sin embargo, las condiciones de trabajo en las embarcaciones no se ajustaban a su letra. Muy por el contrario, los montos y forma de los salarios, el contrato, la jornada laboral, la habitabilidad, alimentación y alojamiento a bordo, entre otras, fueron campo de disputa entre las empresas y los trabajadores, los que a partir de sus organizaciones sindicales actuaron en post de revertir las deterioradas condiciones de trabajo que predominaban a principio de siglo, y sobre todo, en los años de la Primera Guerra Mundial.

En este sentido uno de los primeros logros de la Sociedad de Marineros y Foguistas fue, en 1904, el abolir la costumbre de las empresas a obligar al trabajador de una embarcación particular a trabajar en distintos buques de la misma compañía. A partir de entonces cada tripulación sólo debía abocarse a las tareas de la embarcación para la que fue contratada. ${ }^{37}$

LUM No. 7, 23 de agosto 1911.

37 Boletín del DNT No. 40, febrero 1919. 
Las compañías de navegación solían responsabilizar a los obreros por las averías o daños, imponiendo multas que descontaban de sus salarios. Similar situación se generaba ante la desaparición o robo de los instrumentos o carga de las embarcaciones. Entonces, la empresa intentaba hacer que los trabajadores paguen la pérdida, como ocurrió en los vapores Helios y Berna, de la empresa Mihanovich, donde se intentó que serenos y timoneles pagasen por la desaparición de relojes de la sala de mandos, evitándose por la oposición unánime de delegados de la FOM y de la Sociedad de Capitanes y Prácticos..$^{38}$

Las formas de contratación de las tripulaciones se caracterizaron por una alta informalidad, realizada a partir del conocimiento mutuo y mediante contratos de palabra. ${ }^{39}$ El único requisito que se impuso al comenzar el siglo XX fue el de poseer una libreta de navegación expedida por la Prefectura. Por lo general, los trabajadores eran contratados por los patrones, capitanes o pilotos, "quienes saben escoger la tripulación... a partir de la recomendación o del conocimiento previo". ${ }^{40}$ Existían también contratistas o corredores de embarques, intermediarios que, a cambio de una comisión de no más del $8 \%$ aproximadamente, los ubicaban en alguna embarcación, pero eran una minoría. Abundaban los casos en los que el contacto se daba entre conocidos, vecinos, miembros de la misma colectividad o comunidad de origen, $\mathrm{u}$ otras formas de relación directa. ${ }^{41}$

En materia de salarios, existió una escala correspondiente a la jerarquía y estratificación de las tareas. El informe de Juan Alsina, ${ }^{42}$ realizado en el año 1905, daba cuenta de los montos salariales y las distancias existentes entre un marinero, quien recibía entre $\$ 40$ y $\$ 60 \mathrm{~m} / \mathrm{n}$ al mes, y un capitán, cuyo pago oscilaba entre $\operatorname{los} \$ 250$ y $\$ 300 \mathrm{~m} / \mathrm{n}$, cinco veces más que los tripulantes de cubierta. Un práctico podía superar los $\$ 300 \mathrm{~m} / \mathrm{n}$. Mientras un jefe de sala de máquina ganaba entre $\$ 150$ y $\$ 230 \mathrm{~m} / \mathrm{n}$, un foguista no superaba los $\$ 80 \mathrm{~m} / \mathrm{n}$. En la sección cocina, el encargado o cocinero podía ganar $\$ 80 \mathrm{~m} / \mathrm{n}$, un mozo alrededor de $\$ 50 \mathrm{~m} / \mathrm{n}$, y un lavaplatos menos de la mitad.

En el año 1908, el salario promedio de un marinero continuaba rondando los $\$ 60 \mathrm{~m} / \mathrm{n}$., manteniéndose las proporciones y escalas antes mencionadas. ${ }^{43} \mathrm{La}$ situación se agravó aún más con la rebaja salarial de $\$ 10 \mathrm{~m} / \mathrm{n}$, realizada por las empresas al comenzar la Gran Guerra, lo cual perjudicó el salario nominal, a la par que el salario real se veía deteriorado por el aumento de precios en pleno conflicto bélico. Este fue uno de los reclamos que impulsaron a la huelga general a los trabajadores marítimos de fines del año 1916.

LUM No. 54, agosto 1919, p. 3.

39 Pablo Storni, "La industria y la situación de las clases obreras en la capital de la república. Informe presentado a Joaquín V. Gonzáleza como antecedente para la preparación del Proyecto de Ley Nacional del Trabajo", en Revista Jurídica y de Ciencias Sociales tomo 1, Nos. 1 y 2, Buenos Aires, 1908.

${ }_{40}$ Boletín DNT No. 6, septiembre 1908, p. 368.

41 Boletín DNT No. 6, septiembre 1908.

42 Juan Alsina, El obrero en 1905, tomo 2, cap. 9.

43 Boletín DNT No. 6, Septiembre 1908, pg. 367. 
Diariamente, la mayoría de los tripulantes realizaban horas extras, cuyo pago variaba según el tipo y función de embarcación (trabajo nocturno, domingos o feriados). ${ }^{44} \mathrm{Al}$ sumar las horas extras trabajadas, el salario promedio mensual de un marinero embarcado se aproximaba a los $\$ 80 \mathrm{~m} / \mathrm{n}$. Si tenemos en cuenta que el costo de vida para una familia obrera, calculado por el DNT en el año 1911 , era de $\$ 93,05 \mathrm{~m} / \mathrm{n}$ (incluyendo alquiler, transporte, alimentos, ropa y lavado), queda en evidencia que un marinero que ganaba en promedio entre $\$ 60$ y $\$ 65 \mathrm{~m} / \mathrm{n}$ de salario básico, estaba claramente obligado a trabajar horas extras. Lo ajustado del salario llevaba también a comprar productos en los almacenes cercanos al puerto a través de un sistema de libretas, que muchas veces implicaba un creciente endeudamiento. ${ }^{45}$

Siendo necesarias las horas extras para completar el salario de los trabajadores embarcados, aparecen en reiteradas oportunidades quejas en la prensa gremial sobre el retraso o falta de pago de las mismas, bajo la responsabilidad de los armadores y con la intermediación de capitanes y oficiales. ${ }^{46}$ Otra demanda salarial fue la exigencia de incluir como horas extras el pago de las tareas de salvataje, ineludibles en los casos de accidentes o naufragios. ${ }^{47}$ Así, el incumplimiento del pago salarial en tiempo y forma fue una constante en esos años. Casos como el del vapor Deseado, en el que su propietario "no puede ser más avaro de lo que es, pues de tres a cuatro meses que les adeuda a los foguistas, cuando estos han ido a reclamar sus salarios les ofrece cinco o diez pesos para ir "tirando", como él dice..." eran frecuentes. ${ }^{48}$

El descanso dominical fue también una demanda obrera constante hasta 1905, cuando fue sancionado por ley, y los obreros en general, junto a los marítimos, pasaron a reclamar por el respeto a la ley en cuestión. ${ }^{49}$ Cuando no se hallaban cumpliendo turnos de trabajo, los obreros embarcados se dedicaban a "hacer rancho", esto es, a pasar el tiempo libre en sus camarotes o ranchos o en los espacios comunes habilitados, o a descansar. Pero esto ocurría la menor parte del día. Si bien existió la tendencia a establecer una jornada de ocho a nueve horas según la sección, la jornada laboral de un foguista u otro trabajador de sala de máquinas en los primeros años del siglo se acercaba a las doce horas, lo mismo en cubierta. Es sintomático el caso ocurrido a bordo de un remolcador de una pequeña empresa, donde

los dos foguistas... se desembarcaron porque no pudieron tolerar por más tiempo el abuso de que se les hacía víctimas, obligándolos a trabajar jornadas brutales, como son las de doce horas por día." [La embarcación salió del puerto] "a vista y paciencia de las autoridades marítimas con

P. Storni, "La industria".

5 Boletín DNT No. 19, diciembre 1911.

"Notas y comentarios de la vida de a bordo", en LUM No. 43, octubre 1916.

LUM No. 67, septiembre 1920.

48 LUM No. 44, noviembre 1916, p. 4, "Vapor Deseado" y "Vapor Mar del Plata".

49 José Panettieri, Las primeras leyes obreras, Buenos Aires, CEAL, 1984. El descanso dominical fue sancionado como ley No. 4661 en agosto de 1905. 
un solo foguista, haciendo el trabajo de foguistas el señor maquinista y un traidor de nuestro gremio, que figura como cabo". ${ }^{50}$

Como lo refleja la cita anterior, la intensidad del trabajo y la duración de la jornada estaban estrechamente relacionadas con la composición de la tripulación, es decir, con la cantidad necesaria de personal para cubrir los turnos diarios. Así, el personal mínimo a bordo estuvo desde principios de siglo reglamentado por la Prefectura y sancionado por decretos presidenciales, en donde se estipulaba para cada tipo de embarcación una cantidad necesaria de tripulantes. Esto era lo que ocurría, y así fue analizado por la prensa sindical:

No es posible admitir que embarcaciones de 100 a 1.000 toneladas tengan 1, 2, 3, 4, 5 y 6 marineros respectivamente. En las lanchas y pontones de puerto y río es donde se nota más la falta de personal, ¿cómo admitir que en lanchas que cargan 300 toneladas tengan dos marineros que deben de trabajar, y otro de a ratos, y en aquellos que es uno sólo tiene que ir temprano al mercado, quedarse todas las noches a bordo, trabajar y a la vez atender la cocina?... Con el personal de máquinas ocurre otro tanto. Hay buques que tiene 3 o 4 señores hornos con un foguista que debe permanecer cuatro horas continúas frente a ellos sin descansar un instante de manejar la pala, el nodo y la barra. Por la escasez de carbón se quema leña y ocurre generalmente que el foguista debe manejar trozos de quebracho que tienen de peso de 70 a 80 kilos y para el que ha quemado esta clase de leña sabe lo que es hacer una guardia. ${ }^{51}$

En su informe de 1904 Pablo Storni también denunciaba la ausencia de la cantidad necesaria de trabajadores a bordo, que recargaba el trabajo de los embarcados y empeoraba las condiciones y ritmos laborales, aumentando incluso las posibilidades y probabilidades de accidentes. ${ }^{52} \mathrm{El}$ reiterado incumplimiento de las empresas en cuanto a la cantidad mínima de tripulantes por sección llevó al conflicto con los sindicatos marítimos, los que también debieron enfrentar los intentos patronales de reducir el número de personal. ${ }^{53}$

En cuanto a los accidentes de trabajo, durante los primeros años del siglo XX fueron frecuentes y producto de variadas causas. La seguridad del viaje dependía de múltiples factores, entre ellos, la construcción y el mantenimiento del buque, su conservación y estabilidad, limpieza y calafateado del casco, el respeto al límite de carga, entre otros. ${ }^{54}$ Las condiciones de seguridad a bordo no parecen

${ }_{50} \quad$ LUM No. 44, noviembre 1916.

51 Eduardo Pereyra, "Necesidades de nuestra organización”, en LUM No. 67, septiembre 1920.

52 P. Storni, "La industria".

53 LUM No. 84, abril 1922; No. 86, junio 1922.

54 R.Fold Morell, "Las condiciones de vida a bordo", en AA.VV., Introducción a la historia marítima, Buenos Aires, Fundación Argentina de Estudios Marítimos, 1978. 
haber sido satisfactorias, ya que cumplir con todos los cuidados y disposiciones implicaba para los armadores un enorme gasto, que no siempre se veían obligados a realizar, ya que era evidente la falta de inspección y de sanciones por parte de las autoridades estatales.

El periódico sindical daba cuenta de la falta de elementos de salvataje para la seguridad del personal, debido a la "avaricia de los armadores y por una despreocupación absoluta hacia los que arriesgan sus vidas a bordo." Denunciaba así el incumplimiento de las ordenanzas existentes, que sólo se lograba mediante la paralización del trabajo por las tripulaciones sindicalizadas.

No es posible despreciar así las vidas en aras de la patraña capitalista: porque una cosa es estar en tierra, en lo firme, y otra cosa es vivir horas de angustia en medio del mar donde no hay ramas para agarrase... [Sin botes ni salvavidas, los barcos zarpaban sin llevar a bordo] "bolsa de galleta, el barril del agua dulce, el compás, las velas, el hacha, cohetes, faroles y todo lo necesario en caso de naufragio. ${ }^{55}$

Barcos que zarpan casi completamente desprovistos de los elementos de salvataje, sin cumplir con las precauciones y normas de seguridad a bordo, navegaban y realizaban sus tareas de flete incumpliendo las reglamentaciones, con al anuencia de la Prefectura y Aduana en muchos casos. Muy a pesar de que el seguro por accidente fue obligatorio desde el año 1903, las faltas e incumplimientos por parte de las empresas fueron la norma. Los armadores debían pagarles a los trabajadores accidentados durante el tiempo que no pudieran embarcarse, pero en la práctica este monto se descontaba de los salarios del resto de la tripulación. La indemnización, además, sólo cubría accidentes ocurridos en horas laborables, y muchas veces sólo se ponía en práctica en caso de muerte o de graves consecuencias. ${ }^{56}$ La ley sobre accidentes de trabajo, sancionada en $1915,{ }^{57}$ tuvo una aplicación efectiva paulatina, siendo objeto de múltiples cuestionamientos por parte de los gremios marítimos. Eran frecuentes las denuncias de varaduras, averías y demás accidentes en viaje, causados por la impericia de los oficiales, la falta de formación y capacitación, el excesivo trabajo, en intensidad y cantidad de horas diarias, el reducido espacio en sala de máquinas y el cansancio por las jornadas excesivas, entre otras.

Los espacios habitables a bordo, ámbitos comunes y privados, estaban regidos por modos y criterios que determinaban su diseño, plasmados en reglamentaciones que establecían los modos de su construcción. El reducido espacio para el alojamiento de la tripulación era uno de los más frecuentes incumplimientos a estas reglas de habitabilidad, junto con la falta de ventilación y de una iluminación

55 Eduardo Pereyra, "Necesidades de nuestra organización”, en LUM No. 67, septiembre 1920.

56 P. Storni, "La industria".

57 José Panettieri, Las primera. La ley sobre accidentes de trabajo $\mathrm{N}^{\circ} 9688$ fue sancionada en octubre de 1915. 
adecuada, entre otras. ${ }^{58}$ Por ejemplo, la necesidad de mesas para "hacer rancho" y de baños para los foguistas, los que con suerte y sólo dependiendo de la buena voluntad del superior, podían utilizar los baños destinados a los maquinistas, fue denunciada en el pliego de condiciones de la huelga de 1911. Sin embrago, aún en 1916 formaba parte de las demandas obreras que llevaron al gremio marítimo a la huelga..$^{59}$ Los camarotes individuales estaban sólo disponibles para la oficialidad. La tripulación, en cambio, debía ubicarse en espacios reducidos. Un artículo de La Unión del Marino, entre muchos, denunciaba

¿Quién ignora, en efecto, las inmundas pocilgas de algunos barcos, ya sean ellas llamadas camarotes o "ranchos", en donde nos vemos obligados muchas veces a pasar parte de nuestra existencia, con el gravísimo peligro de contraer alguna enfermedad de carácter grave?... No es posible seguir contemplando que gran parte de nuestros hermanos vegeten en habitaciones inmundas, sin ventilación alguna, plagadas de bichos asquerosos, habitaciones que se hacen más odiosas y hediondas cuanto más al norte, a los climas cálidos, van los buques. Barcos hay que se asemejan a ratoneras. De ellas salen los tripulantes como los lagartos de sus cuevas. ${ }^{60}$

En estas condiciones era frecuente la proliferación de diversas enfermedades a bordo, entre las que se mencionan con frecuencia la tuberculosis, la fiebre amarilla, las enfermedades venéreas y el alcoholismo, ${ }^{61}$ habiendo sido descartado el escorbuto. A estas enfermedades se sumaban aquellas relacionadas con factores psicológicos, causadas por el desarraigo, la ansiedad al momento de desembarco ante la posibilidad del deber de permanecer a bordo si no aparecía el relevo, y tener así que continuar en viaje, o también frente a la preocupación, que en determinadas coyunturas se volvía una certeza, de desembarcar sin tener aún contrato para un nuevo viaje en eso $\mathrm{u}$ otro barco. ${ }^{62}$

Tanto el agua potable como los alimentos eran condiciones esenciales para el trabajo en viaje, y objetos de racionamiento. Una de las demandas reiteradas de los sindicatos marítimos, expresadas en las huelgas de $1911^{63}$ y 1916, fue lo que ellos consideraban una alimentación "sana, abundante y variada, compuesta por tres platos y pan fresco, y la sustitución del vino Carlón por el San Juan o Francés". ${ }^{64}$ En diciembre de 1916 se incluyó la provisión de un litro de vino Mendoza, la eliminación de los intermediarios en la provisión de los alimentos y el pase de esta responsabilidad a los cocineros. La mala alimentación y las

${ }^{58}$ P. Storni, "La industria".

${ }^{59}$ Boletín DNT No. 37, marzo 1918.

${ }^{60}$ W. Denda, "Acción conjunta y futuro de nuestra organización", en LUM No. 71, enero 1921.

${ }^{61}$ LUM No. 58, diciembre 1919.

${ }^{62}$ Entrevista realizada en julio 2008 a Alberto Lorenzo, limpiador y luego electricista, hijo y nieto de marineros españoles provenientes de la región del Cabo de Finisterre, Galicia, España.

${ }^{63}$ LUM No. 7, agosto 1911.

${ }^{64}$ Boletín DNT No. 19, diciembre 1911. 
pésimas condiciones existentes antes de la huelga de 1916, llevó a que uno de los marineros del vapor Mar del Plata "indignado por la pésima e insuficiente alimentación que se daba en el buque, reunió la cena y en un paquete postal la envió certificada al presidente del directorio". ${ }^{55} \mathrm{El}$ articulo denunciaba que la causa del deficiente avituallamiento fue la especulación y acaparamiento del los insumos por parte del capitán, situación que se repetía en las embarcaciones de las diversas flotas. La prensa gremial afirmaba que

...los que ignoran la triste situación en que se encuentran los parias de a bordo, foguistas y marineros, no podrán si no justificar la necesidad imperiosa de poner un límite a la rapacidad de proveedores mayordomos, y hasta capitanes poco escrupulosos que medran hasta con la comida de los infelices trabajadores de a bordo, que no trepidan en robar descaradamente lo que los armadores estipulan para la manutención de sus obreros. ${ }^{66}$

Fueron también frecuentes en aquellos años los reclamos por la realización de tareas ajenas al oficio. En este marco se daba la negativa de marinos y foguistas a realizar tareas que su categoría no contemplaba, como pintar las chimeneas o la cubierta, realizar tareas de carga, lavar los costados del barco, y se reflejan diversas protestas contra los despidos. Foguistas que se niegan a la orden del capitán de realizar el trasbordo de leña y de estibarla en las carboneras, o a trasladar canastos de verduras de la proa a la popa; jefes maquinistas que les exigen que pinten las chimeneas del buque, marineros despedidos por negarse a transportar los equipajes de una compañía teatral, como les exigía el capitán, son sólo algunos de los ejemplos citables. ${ }^{67}$

Con relación a las calificaciones, una de las exigencias frecuentes entre los trabajadores marítimos fue la implementación y respeto a los exámenes de aptitudes y conocimientos, tanto para personal de máquinas como de cubierta, estableciendo un período de aprendizaje previo. ${ }^{68}$

¿Por qué no se exige que en todos los buques existan aprendices del trabajo a bordo?"; exigir aprendices para marineros y foguistas "es contribuir a que se valorice el trabajo, exigiendo que para la sección de máquinas tenga por lo menos un año de mozo, y al pasar lo haría como carbonero e ir ascendiendo, y en sección cubierta igual término para pasar primeramente a guinchero y después a marinero. Es necesario realizar el oficio para obtenerlo... ${ }^{69}$

\footnotetext{
${ }^{65}$ LUM No. 44, noviembre 1916, p. 4.

${ }^{66}$ LUM No. 43, octubre 1916; No. 44, noviembre 1916; No. 56, octubre 1919.

${ }^{67}$ LUM No. 43, octubre 1916; LUM No. 54, agosto 1919, p. 3; y LUM No. 56, octubre 1919.

68 "Resoluciones de la Asamblea de Marineros del 10 de julio"; No. 66, agosto 1920 "Necesidades de nuestra organización”, en LUM No. 54, agosto 1919.

69 "Necesidades de nuestra organización”, en LUM No. 67, septiembre 1920.
} 
Las mismas demandas sostenían los maquinistas, quienes denunciaban en forma reiterada el incumplimiento de la reglamentación existente, al contratar foguistas en lugar de maquinistas, "hombres que a duras penas saben poner su nombre y que no han estado jamás en un taller" ${ }^{70}$ La defensa del saber y la formación necesaria para el desarrollo y la práctica de las tareas del maquinista, un trabajo de alta calificación, se expresó también a través del llamado a los trabajadores de menor edad: “... jóvenes obreros, a ustedes les toca el batallar ahora porque la reglamentación sea un hecho... ¿De qué os sirve el rudo aprendizaje en un taller durante 10 o 12 años? ¿De qué os sirve que tras las fatigas de la labor diaria vayan a sacrificarse con el estudio nocturnos durante horas previendo en lontananza un porvenir risueño...". ${ }^{71}$

La ausencia de un reglamento del trabajo a bordo fue uno de los rasgos característicos de esos años, señalado tanto por las organizaciones de los trabajadores como por instituciones estatales, e incluso, en algunas coyunturas, por las organizaciones patronales. Dentro del conjunto de los trabajadores, los marítimos quedaban muchas veces por fuera del campo de aplicación de las leyes existentes para la regulación de las condiciones laborales. Así lo señalaba un importante funcionario del Departamento Nacional del Trabajo, al afirmar que: "el marino se encuentra legalmente menos protegido que el ferroviario o que el trabajador de una fabrica o usina por la propia naturaleza del contrato de trabajo a bordo" ${ }^{72}$ Durante todo el período fue materia pendiente la constitución y aplicación de una reglamentación que determine claramente las obligaciones de la tripulación, así como sus derechos, pero esta situación era similar en otras actividades.

Todos los elementos aquí analizados nos permiten reconstruir una imagen nítida de las condiciones de trabajo marítimo. El éxito de la huelga general marítima de diciembre de $1916,{ }^{73}$ resultó en el mejoramiento de las condiciones de trabajo y en la consolidación y fortalecimiento de la FOM, posibilitándole ejercer el control sobre la organización y condiciones laborales entre 1916 y 1921. Esto reforzó la mejora sustancial de las condiciones generales de trabajo, sólo posibilitadas y sostenidas a partir de la acción directa impulsada por esta federación, la cual contó con una fuerte adhesión de los trabajadores del sector. A la vez, implicó un nivel creciente de enfrentamiento con las empresas. Ambos, los trabajadores marítimos y la patronal naviera, desarrollaron un mayor nivel de organización y de acción, a la par que presionaron de forma creciente y por diversos medios, al Estado Nacional. El conflicto obrero-patronal derivó en la huelga parcial que, durante todo el año 1920, sostuvieron los trabajadores marítimos contra la empresa Mihanovich.

${ }_{70}$ Boletín del Obrero Mecánico, $1^{\circ}$ noviembre 1900.

${ }^{71}$ Boletín del Obrero Mecánico, $1^{\circ}$ noviembre 1900.

72 Boletín DNT No. 47, septiembre 1920, p. 32. Informe de Alejandro Unsain.

73 Boletín DNT No. 37, marzo 1918 y No. 40, febrero 1919, La Unión del Marino No. 44, noviembre 1916. 
Diversas acciones y medidas de lucha impulsadas por la FOM fueron el medio para lograr y mantener el control sobre el acceso al puesto de trabajo, las condiciones de trabajo y la disciplina a bordo de las flotas de cabotaje del Puerto de Buenos Aires a partir de $1916 .{ }^{74}$ La propia organización jerárquica del trabajo marítimo hizo que, para hacer efectivo el control sobre las condiciones y el mercado laboral por parte de la FOM, fuese imprescindible la alianza con las organizaciones de capitanes y demás oficiales, siendo estos parte del personal más calificado de a bordo y por tanto responsables de armar los listados de las diversas tripulaciones, los que debían informar a la empresa y a la autoridad estatal. En tanto se mantuvo la unidad y solidaridad de la tripulación y la oficialidad, se mantuvo el control sindical, el cual fue debilitado recién en 1921.

\section{A modo de conclusión}

La reconstrucción histórica del proceso y organización del trabajo a bordo aquí esbozada tiene, necesariamente, un tono descriptivo. Se ha intentado amalgamar datos y descripciones con el análisis de los problemas fundamentales relacionados, para profundizar en el conocimiento y la reflexión sobre los temas relativos al trabajo marítimo en la última década del siglo XIX y las primeras del siglo XX, en particular, sobre el proceso y la organización a bordo como primer elemento explicativo de las condiciones laborales y los conflictos resultantes, así como su incidencia en la organización obrera y la dinámica de unidad entre diversas categorías de trabajadores marítimos.

Del análisis anterior se desprenden algunas afirmaciones nodales relacionadas con el trabajo marítimo, su organización y proceso de trabajo. Un primer elemento clave en el estudio del trabajo marítimo lo constituye la serie de cambios e innovaciones en su base material, incorporadas por las empresas en función del aumento de la productividad del trabajo. Los más destacados fueron la navegación a vapor, la construcción metálica del casco y de la estructura del barco, y el reemplazo de la máquina a vapor por otros motores, como el de combustión interna. Esta mecanización progresiva del proceso de trabajo tuvo como resultado la desaparición de determinadas tareas a bordo y la aparición de otras, y los trabajadores abocados a estas, como fue la progresiva desaparición de los calafates, los carboneros, caldereteros y foguistas, y la incorporación de engrasadores, electricistas, entre otros. Incluso se incorporaron nuevas secciones enteras, como la de comunicaciones. Si bien el cambio de la navegación a vela a la navegación a motor fue sustancial para la tripulación de cubierta, esta no fue la más afectada por innovaciones posteriores, como sí lo ocurrió con la sala de maquinas. La sección de cocina fue la menos implicada por los cambios en el proceso y en la organización laboral. Estas transformaciones, y la consecuente

\footnotetext{
${ }^{74}$ Un caso semejante de control obrero se dio entre los obreros de la construcción, y en algunos aspectos entre los estibadores, de la ciudad de Santos. Ver Fernando Texeira Da Silva, Operarios sem patróes. Os trabalhadores da cidade de Santos no entreguerras, Sao Paulo, Ed. UNICAMP, 2003.
} 
reducción de la tripulación necesaria, dieron lugar a una gran cantidad de reclamos y de acciones por parte de los obreros embarcados y sus organizaciones.

Segundo, a bordo de vapores y veleros, el trabajo de miles de obreros se organizó en secciones bien diferenciadas, con una estructuración jerárquica. Las principales y perdurables fueron la de cubierta, sala de máquina y cocina. Al interior de cada una de estas existieron múltiples categorías y calificaciones de trabajadores, analizadas en este trabajo. Esta forma de división del trabajo y su organización se estableció sobre una base material y técnica determinada, que caracterizó el proceso de trabajo marítimo. La principal diferenciación establecida por la organización del trabajo a bordo fue la existente entre concepción y ejecución, claramente fragmentada entre la oficialidad y la tripulación, cuya diferenciación a nivel del proceso de trabajo se reprodujo en su organización gremial, a la vez que la unidad de acción que lograron desarrollar en ciertos períodos superó la diferenciación establecida por la experiencia laboral, como base material de intereses e identidades divergentes, aunque no siempre contrapuestos.

De esta forma, el rasgo fundamental de la organización del trabajo a bordo fue la jerarquía y diferenciación establecida entre la tripulación y la oficialidad, así como también al interior de las secciones mencionadas. La jerarquía que caracterizó la organización laboral al interior de las embarcaciones fue considerada un elemento indispensable para la supervivencia misma de los embarcados, concepto compartido por tripulantes, oficiales, funcionarios y empresario, además de hacer posible el desarrollo de la actividad de navegación comercial con éxito. Esta jerarquía se expreso tanto en una organización gremial diferenciada, y, si bien existieron relaciones conflictivas a bordo y denuncias contra abusos de autoridad, no alcanzaron a impugnar la existencia misma de esa diferenciación. A pesar de las diversas categorías y secciones, existió un consenso general en torno a la organización jerárquica y piramidal del trabajo, estructurada ante la necesidad de respetar la división jerárquica como factor de supervivencia. Sin embargo, en ciertas coyunturas de enfrentamiento con las empresas, esta diferenciación no impidió la unidad de acción entre la oficialidad - el personal jerárquico y calificado - y las tripulaciones, enfrentándose de manera unitaria, y por esto eficaz, a la hostilidad creciente de la patronal. A través de estas acciones se buscó solucionar y mejorar condiciones de trabajo a bordo deterioradas y fuera de toda ley, como ocurrió durante gran parte del período con la habitabilidad y la seguridad, la jornada laboral, el pago de salarios y horas extras, entre otras. A partir del año 1916, la lucha sindical marítima, enmarcada y retroalimentada por una coyuntura política nacional y mundial de creciente intensidad de la lucha de clases, fue exitosa. La acción obrera, en conjunto con las organizaciones de la oficialidad, impuso nuevas condiciones y enfrentó el incumplimiento reiterado de la reglamentación existente. 


\section{Bibliografía}

\section{Fuentes primarias: Periódicos, censos, entrevista.}

Boletín del Departamento Nacional del Trabajo, 1908, 1911, 1918, 1920

Boletín del Obrero Mecánico, 1900.

Entrevista realizada en julio 2008 a Alberto Lorenzo, limpiador y luego electricista, hijo y nieto de marineros españoles provenientes de la región del Cabo de Finisterre, Galicia, España.

La Unión del Marino, 1916, 1920, 1919, 1921, 1922.

Recopilación de antecedentes que interesan a la Marina Mercante y Policía Marítimas, Buenos Aires, 1937, pp. 386-389.

Segundo Censo de la República, Buenos Aires, Talleres Tipográficos de la Penitenciaría Nacional, 1898.

Tercer Censo Nacional levantado el 1ro. de junio de 1914, tomo 10, Buenos Aires, Talleres Gráficos de L. J. Rosso, 1916-1917.

\section{Fuentes Secundarias: Libros y artículos.}

A. y A. González Climent, Historia de la Marina; Recopilación de antecedentes que interesan a la Marina Mercante y Policía Marítimas, Buenos Aires, 1937.

Alejandro Belkin, Sobre los orígenes del sindicalismo revolucionario en Argentina, Departamento Historia, Buenos Aires, CCC, 2007.

Aurelio y Anselmo Climent González, Historia de la Marina Mercante Argentina, tomo IV, Buenos Aires, 1972.

Daniel Kersffeld, George Sorel: apóstol de la violencia, Buenos Aires, Signo, 2005.

Edgardo Bilsky, La FORA y el movimiento obrero /1, Buenos Aires, CEAL, 1985.

Fernando Texeira Da Silva, Operarios sem patróes. Os trabalhadores da cidade de Santos no entreguerras, Sao Paulo, Ed. UNICAMP, 2003.

José Panettieri, Las primeras leyes obreras, Buenos Aires, CEAL, 1984.

Juan Alsina, El obrero en 1905, tomo 2, cap. 9.

Luis Ario Russo, La marina mercante argentina, Buenos Aires, Instituto de Economía de los Transportes/FCE/UBA, 1938.

Maricel Bertolo, Una propuesta gremial alternativa: el Sindicalismo Revolucionario (1904-1916), Buenos Aires, CEAL, 1993.

Hugo Del Campo, El sindicalismo revolucionario (1905-1940), Buenos Aires, CEAL, 1986.

Mirta Lobato, La vida en las fábricas. Trabajo, protesta y política en una comunidad obrera, Berisso (19041970), Buenos Aires, Prometeo, 2001.

Ofelia Pianetto, "Mercado de trabajo y acción sindical en la Argentina, 1890-1922" en Desarrollo Económico vol. 24, No. 94, Santiago, Cepal, 1984. 
Oscar Troncoso, Fundadores del gremialismo obrero, vol. 1, Buenos Aires, CEAL, 1983, p. 56.

Pablo Storni, "La industria y la situación de las clases obreras en la capital de la república. Informe presentado a Joaquín V. González como antecedente para la preparación del Proyecto de Ley Nacional del Trabajo", en Revista Jurídica y de Ciencias Sociales tomo 1, Nos. 1 y 2, Buenos Aires, 1908.

R.Fold Morell, "Las condiciones de vida a bordo", en AA.VV., Introducción a la historia marítima, Buenos Aires, Fundación Argentina de Estudios Marítimos, 1978.

Roberto Bloch, “La figura del Capitán”, en Revista Marítima, Buenos Aires, abril 1999.

Víctor Wagner Neto De Oliveira, Entre o Prata e Mato Gresso: uma viagem pelo mundo do trabalho marítimo de 1910 a 1930 (Buenos Aires, Montevidéu, Assunção e Corumbá), Campinas, UNICAMP, 2006.

Yadira De Las Cuevas Potrony, "Regulación Jurídica de la gente de mar. Aspectos significativos en el ordenamiento jurídico cubano”, en Revista Académica No. 33, La Habana, Equipo Federal de Trabajo, 1989. 
